\title{
Overmedicated minerals: pharmaceutical sorption to iron oxides
}

JANICE P. L. KENNEY ${ }^{1}$, JONATHAN P. RITSON ${ }^{2}$, HANNAH L. RIGBY ${ }^{3}$

${ }^{1}$ MacEwan University, Canada, janice.kenney@macewan.ca ${ }^{2}$ Imperial College London, UK, j.p.ritson@protonmail.com

${ }^{3}$ Imperial College London, hannah.rigby04@imperial.ac.uk

Many countries are using treated sludge (i.e. biosolids) as a sustainable farming practice to apply to agricultural fields as a way of replacing geologically mined phosphate. For example, Canadians produce approximately 660,000 metric tons of dry biosolids each year. Recycling nutrient-rich sewage sludge on land reduces the use of manufactured fertilizers and has been shown to be cheaper than the cost of commercial synthetic fertilizers. However, pharmaceuticals imbibed by humans can still be present in these biosolids after treatment and have been shown to be detrimental to downstream ecosystems.

In this study we use Fourier transform infrared (FTIR) spectroscopy to examine the behaviour of pharmaceutical compounds, which have been identified from biosolid runoff, at the mineral-water interface. The pharmaceuticals in this study include Ciprofloxacin and Oxytetracycline, both of which are antibiotics, as well as the heartburn medication Ranitidine. The mineral interface studied was that of the iron oxide goethite.

We found that sorption of the pharmaceuticals was $\mathrm{pH}$ dependent, with maximum adsorption at $\mathrm{pH} 7$ for Ciprofloxacin and at pH 3 for Oxytetracycline. Ranitidine did not sorb to goethite to any appreciable extent. We further studied the sorption of Ciprofloxacin, using FTIR spectroscopy as a function time at $\mathrm{pH} 7$ on the goethite surface. We found that after $24 \mathrm{~h}$ over $50 \%$ of the Ciprofloxacin was oxidized and remained on the goethite surface. 